\title{
Bilateral Accessory C1 and C2 Facet Joints; Clinical, Neuroradiological and Peroperative Findings in an Adult with Quadriparesis
}

\section{Acessórios faciais bilaterais C1 e C2; Achados clínicos, neurorradiológicos e peroperatórios em um adulto com quadriparesia}

Forhad H. Chowdhury ${ }^{10}$ Mohammod Raziul Haque ${ }^{3}$ Maliha Hakim² Mohammod Shamsul Arifin ${ }^{3}$ Soyed Ariful Islam ${ }^{3}$

${ }^{1}$ Department of Neurosurgery, National Institute of Neurosciences Address for correspondence Forhad H. Chowdhury, FCPS, and Hospital, Dhaka, Bangladesh

2 Department of Neurology, National Institute of Neurosciences and Department of Neurosurgery, National Institute of Neurosciences and Hospital, Dhaka, Bangladesh

${ }^{3}$ Department of Neurosurgery, Bangladesh Specialezed Hospital, Hospital, Shere-e-bangla nagar, Dhaka, 1207, Bangladesh (e-mail: forhadchowdhury74@yahoo.com).

Dhaka, Bangladesh

Arq Bras Neurocir 2019;38:328-335.

\begin{abstract}
Objectives Accessory C1 and C2 facet joints are very rare. Only few cases were reported in the literature. We report a case of bilateral accessory facets in an adult with

Keywords special attention to clinical, neuroradiological, as well as peroperative findings.

- accessory atlantoaxial facet joint

- C1 and C2 accessory facets

- craniovertebral junction

- instability

- quadriparesis

- adult Case report A 37-year-old male presented with progressive quadriparesis. Radiology revealed bilateral posterior accessory $\mathrm{C} 1$ and $\mathrm{C} 2$ facet joints compressing the spinal cord with craniovertebral junction (CVJ) instability. Both accessory $\mathrm{C} 1$ and $\mathrm{C} 2$ facets with the posterior arch of the $\mathrm{C} 1$ were removed. Lateral mass screws and plates fixation at the $\mathrm{C} 1$ and $\mathrm{C} 2$ level, as well as fusion, were performed. Postoperatively, the patient recovered well.

Conclusion In accessory C1 and C2 facet joints, when symptomatic, neuroradiological findings can guide to the proper diagnosis, to pathological understanding, and, ultimately, to management strategy.
\end{abstract}

\section{Introduction}

Common craniovertebral junction (CVJ) skeletal deformities are basilar invagination, occipital assimilation of the $\mathrm{C} 1$, platybasia, os odontoideum, foramen magnum stenosis, and skeletal deformities associated with Chiari malformations, among others. ${ }^{1}$ Accessory facet joints or supernumerary facets between the $\mathrm{C} 1$ and the $\mathrm{C} 2$ is a very rare anomaly, and only a few cases of this condition have been reported in

received

February 1, 2019

accepted

March 20, 2019
DOI https://doi.org/

10.1055/s-0039-1688460. ISSN 0103-5355. the literature. The origin, anatomical descriptions, functions and pathological associations of these joints still remain to be defined. In the present work, we report a case of bilateral accessory facets in which an adult patient presented with quadriparesis (due to $\mathrm{C} 1$ and $\mathrm{C} 2$ instability and spinal cord compression by the accessory facet joints from back), where special attention was given to clinical, neuroradiological, as well as peroperative findings.

Copyright @ 2019 by Thieme Revinter Publicações Ltda, Rio de Janeiro, Brazil

License terms

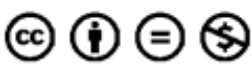




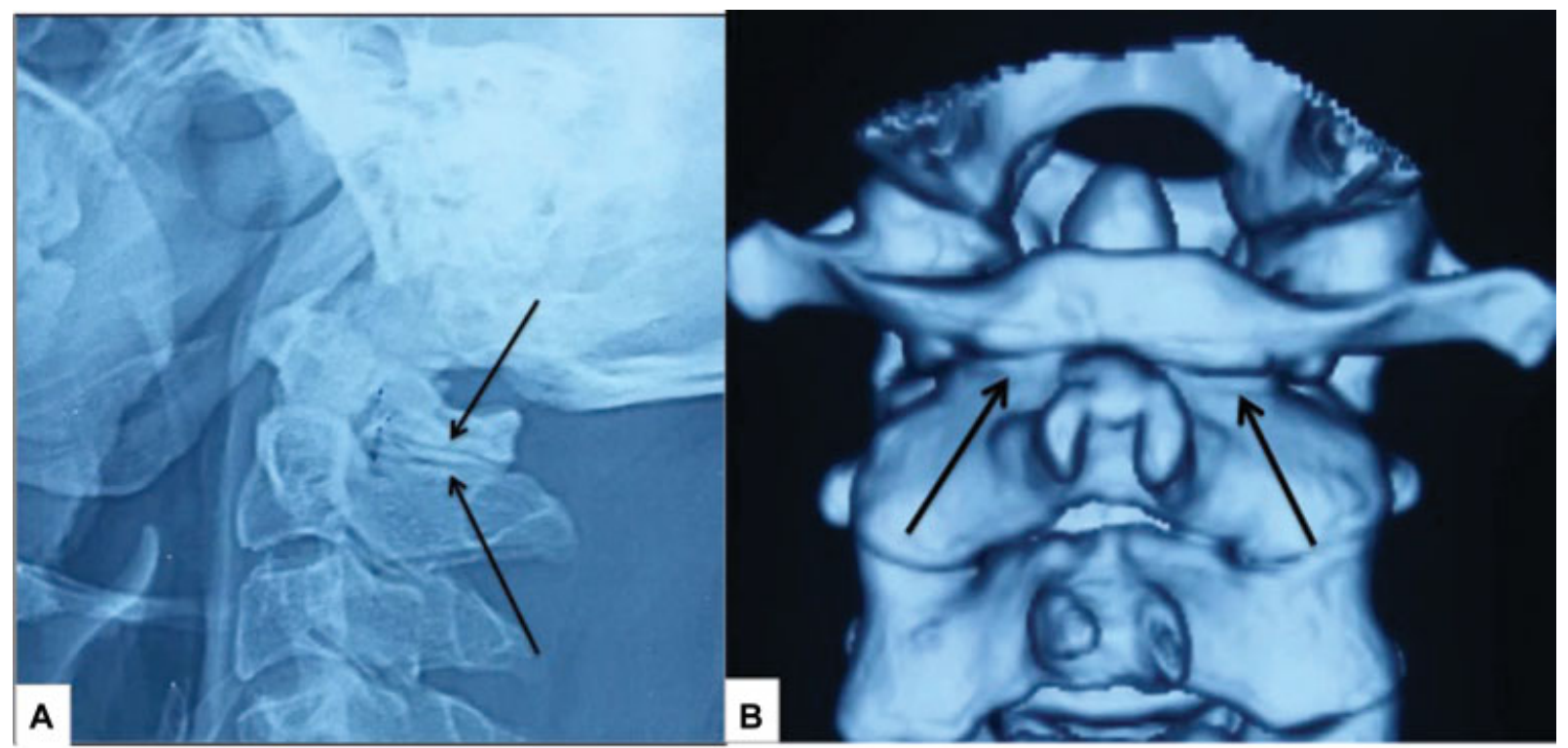

Fig. 1 A - X-ray of the cervical spine (lateral view) showing the C1 and C2 accessory facet joint (arrow marked); B- 3D computed tomography scans of the craniovertebral junction (posterior view) showing bilateral C1 and C2 accessory facet joints (arrow marked).

\section{Case Report}

A 37-year-old male presented with neck pain and weakness of all limbs for 15 days. The weakness was progressive in nature, due to which he was unable to stand and walk for the last few days of his complaints. He had no history of trauma. His neck movements were restricted and painful, especially in the upper cervical spine. There was tenderness at the CVJ. His muscle power was Medical Research Council (MRC) grade 3־/5 in all limbs. The Hoffman sign was bilaterally positive and the planter reflex was extensor on both sides. All of the tendon jerks were exaggerated. All of the modalities of sensation were reduced $40 \%$ bilaterally up to the C2 dermatome.

\section{Neuro-Radiology}

An X-ray of the CVJ seemed to be normal at first, but a careful observation of the lateral view showed a joint between the $\mathrm{C} 1$ arch and the C2 lamina, characterized by two articular surfaces and a joint space. The $\mathrm{C} 1$ posterior arch and the $\mathrm{C} 2$ neural arch seemed to be bigger and heavier than usual (-Fig. 1A).

Computed tomography (CT) scans of the CVJ showed that the $\mathrm{C} 1$ posterior arch and that the $\mathrm{C} 2$ neural arch were bigger and heavier than usual. There was a knob-like elongation of the lateral part of the posterior arch of the $\mathrm{C} 1$ just posterior to the lateral mass on both sides. The same type of knob-like bony formations were also found at the laminopedicular junction of the $\mathrm{C} 2$ bilaterally. Together, these bony elongations formed accessory facets joints on both sides that compromised the spinal canal from the back. Odontoid was shifted to left as seen in axial films indicate atlantodental joint instability. The vertebral foramina and the vertebral arteries seemed to be normal (-Figs. 1B, 2, \& 3).

Magnetic resonance imaging (MRI) of the CVJ showed compression of the spinal cord at the $\mathrm{C} 1$ and $\mathrm{C} 2$ level from

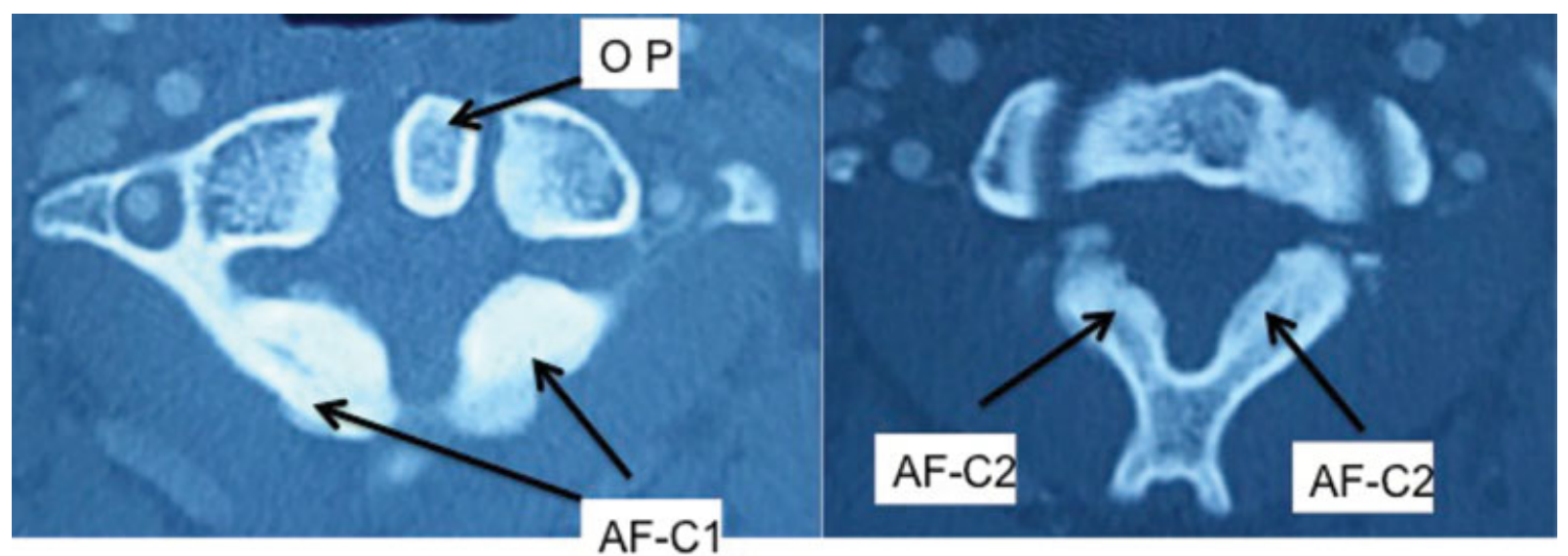

Fig. 2 Computed tomography scan axial views of the craniovertebral junction showing accessory articular facets of the $C 1$ and $C 2$, respectively (left and right). The left side also shows atlantodental joint dislocation. Abbreviations: AF-C1: accessory facet C1; AF-C2: accessory facet C2; OP: odontoid process. 


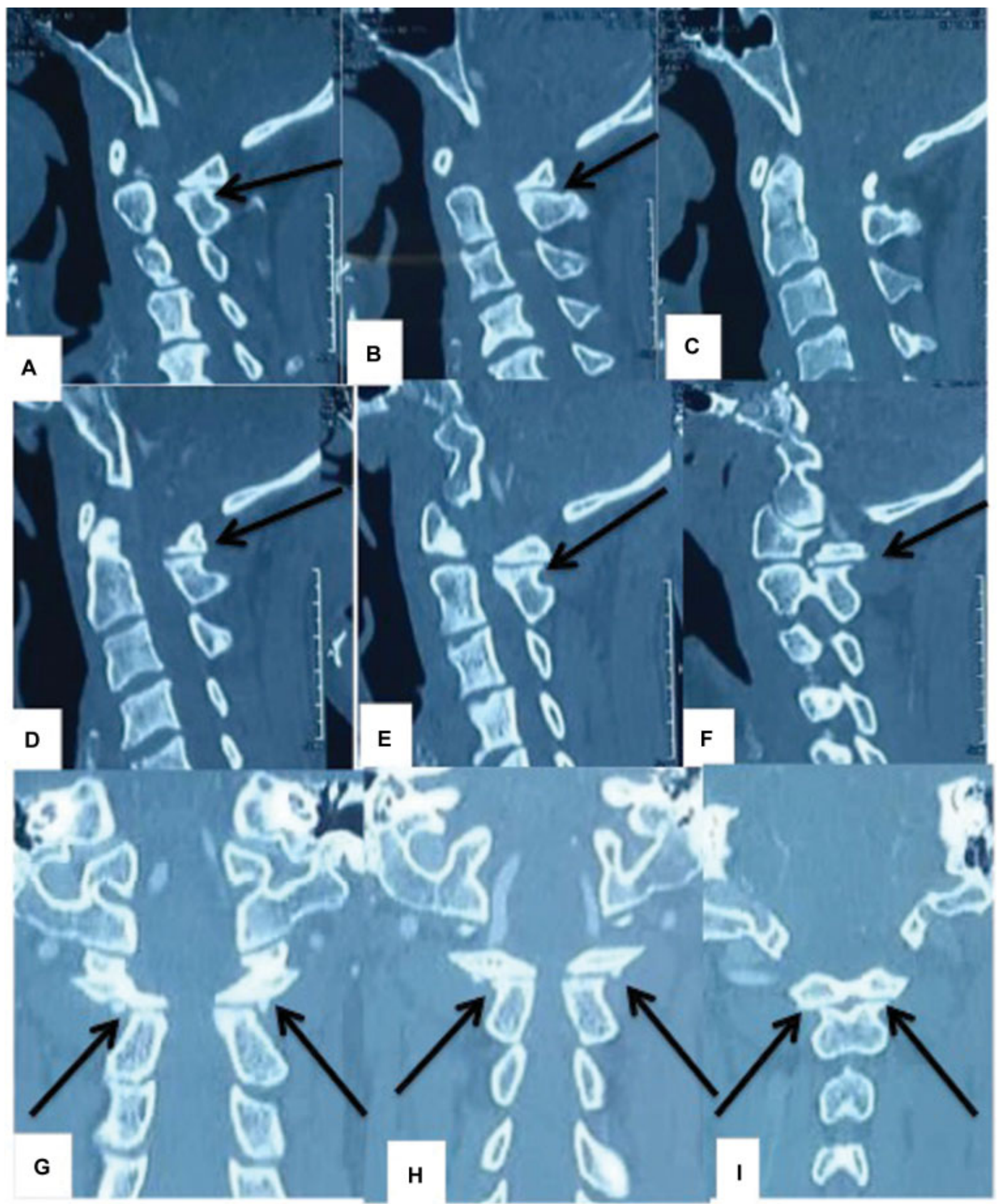

Fig. 3 Computed tomography scan (bony windows) of the craniovertebral junction. A, B, C, D, E, and F: serial sagittal sections (left to right) showing bilateral accessory facet joints between the $C 1$ and the $C 2$ (arrow marked); $G, \mathrm{H}$ and I: serial coronal sections A, B, C and D: Showing bilateral accessory facet joints between the $\mathrm{C} 1$ and $\mathrm{C} 2$ (arrow marked)

back with spinal cord signal changes from the $\mathrm{C} 4$ to the medulla oblongata. Careful observation also showed two more facet joints posterior to the regular facet joint that were compressing the spinal cord from back ( - Fig. 4). Paramedian sagittal cuts in T2-weighted MRI showed heavy accessory facets that were easily identified with linear joint space (that is, linear hyperintensity). Spinal cord compres- sion and signal changes indicated instability in the regular $\mathrm{C} 1$ and C2 facet joints (-Fig. $\mathbf{5}$ ).

Dynamic X-ray or dynamic CT scan were not performed since the spinal cord was already compressed with signal changes and the accessory facets narrowed the spinal canal. (In the CT scan and MRI images, there were signs of $\mathrm{C} 1$ and $\mathrm{C} 2$ instability.) 


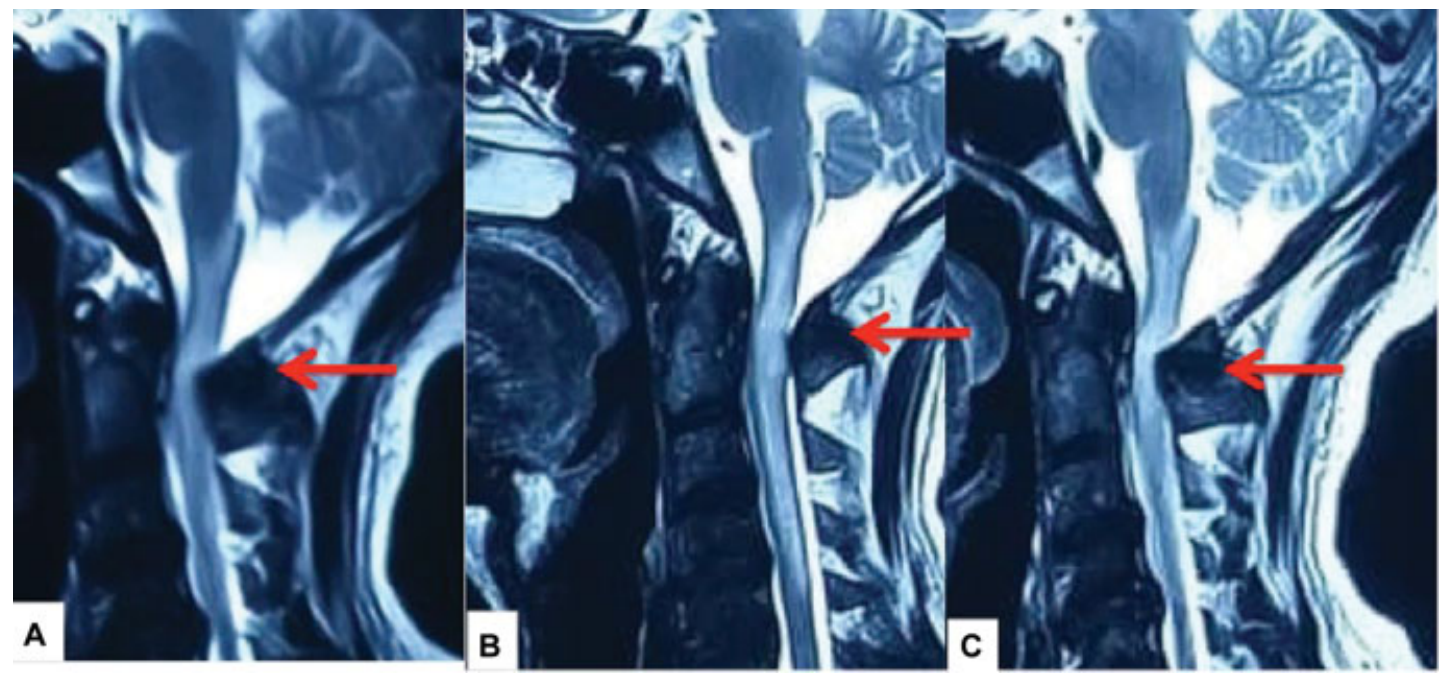

Fig. 4 T2-weighted magnetic resonance imaging of the craniovertebral junction, sagittal images . A, B, and C: Compression of the spinal cord from the back (arrow marked) with signal changes in the spinal cord.

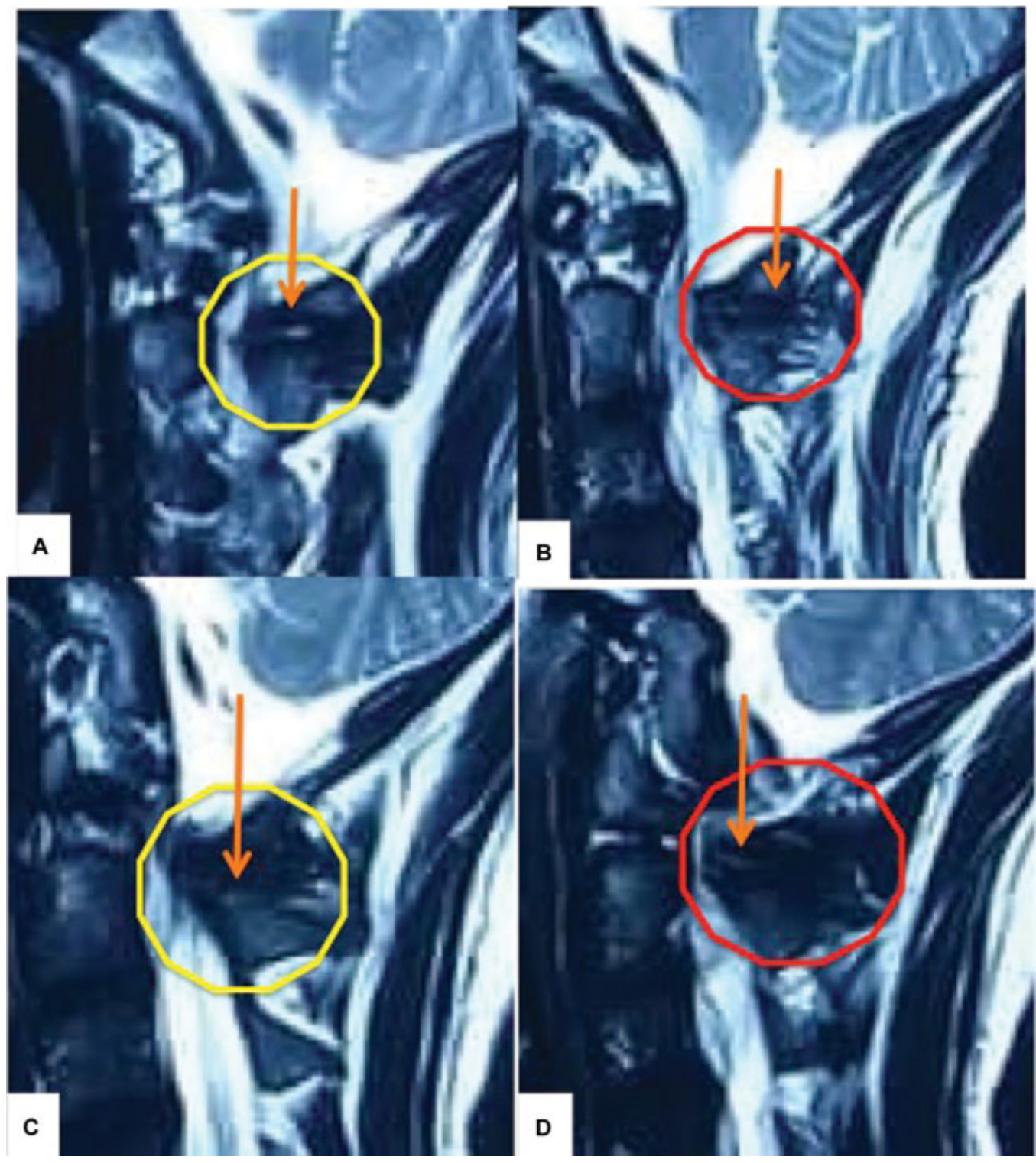

Fig. 5 Magnetic resonance imaging of the craniovertebral junction. A and B: left-sided paramedian; C and D: right paramedian sagittal T2weighted images showing accessory facets (within the circle) and linear hyperintense joint cavity (arrow marked). 


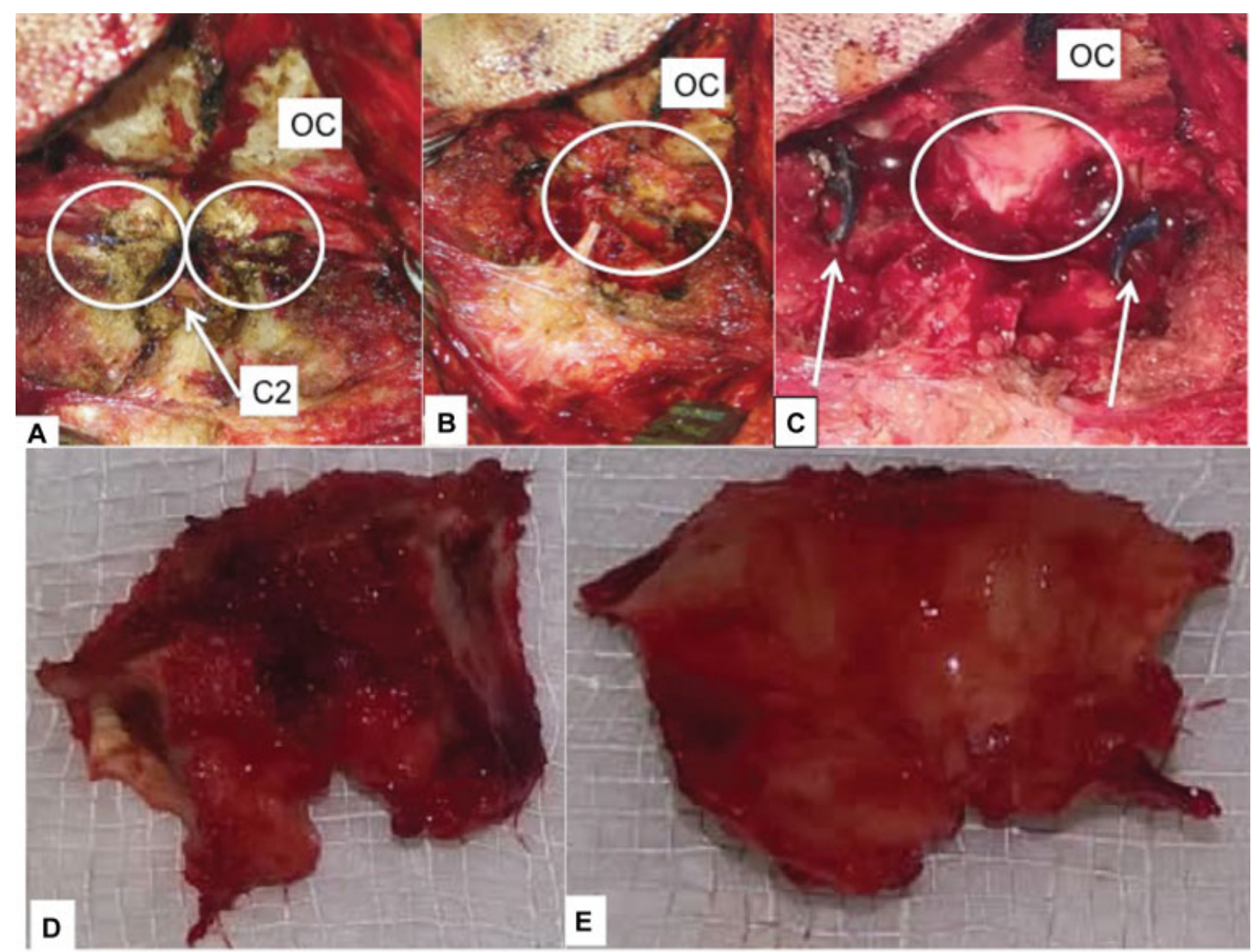

Fig. 6 Peroperative pictures after the exposure of the craniovertebral junction, A: showing both accessory facet joints within the circle and the C2 spinous process (arrow marked),; B: after the removal of both accessory facets with the C1 posterior arch (circle marked area); C: after the removal of both accessory facets with the $C 1$ posterior arch and after the removal of the posterior atlanto-occipital and atlantoaxial ligaments (circle marked area). Fixation of the lateral mass screws and of the plate are also seen (arrow marked). OC-occiput; D and E: after the removal of both $\mathrm{C} 1$ accessory facets and of the $\mathrm{C} 1$ posterior arch as a single piece. interior surface \& exterior surface respectively

\section{Planning}

After counseling with the patient party, decompression of the spinal cord by removing both accessory facet joints along with the $\mathrm{C} 1$ posterior arch, as well as $\mathrm{C} 1$ and $\mathrm{C} 2$ lateral mass screws and plate fixation and fusion were planned.

\section{Operation and Operative Findings}

The patient underwent the operation under general anesthesia with endotracheal intubation in the prone position. Skull traction was set to keep the neck in the neutral position and the head end was elevated to counteract the skeletal traction and also to ease venous drainage of the head and the neck. The occiput, the posterior arch of the $\mathrm{C} 1$, the spinous process, the lamina of the $\mathrm{C} 2$, and both the $\mathrm{C} 1$ and $\mathrm{C} 2$ facet joints (that is, the CVJ) were exposed completely from the back. Two extra facet joints were found between the $\mathrm{C} 1$ and the $\mathrm{C} 2$ posterior to the normal facet joints. The $\mathrm{C} 2$ nerve root and ganglion came out laterally between the regular and accessory facets bilaterally. The $\mathrm{C} 2$ accessory facets were smaller than the $\mathrm{C} 1$ accessory facets. The right and left accessory facet joints were asymmetric and un- equal ( - Fig. 6A). The C2 part of the accessory facets were removed by using a high-speed drill under a microscope. Then, the $\mathrm{C} 1$ part of the accessory facets were also removed by drilling along with the $\mathrm{C} 1$ posterior arch in a single piece (-Figs. 6B, C, D \& E). After the removal of both accessory facets and of the $\mathrm{C} 1$ posterior arch, spinal cord pulsation returned. The $\mathrm{C} 1$ accessory facets compressed the spinal cord more than the $\mathrm{C} 2$ accessory facets. In both accessory facets, there were articular cartilage and a pannus-like synovial membrane. After the decompression of the spinal cord, both regular C1 and C2 facet joints were checked and found to be unstable. The regular $\mathrm{C} 1$ and $\mathrm{C} 2$ facet joints were opened and the articular cartilages were denuded. Joint fusion and jamming ${ }^{2}$ were performed with autologous bone chips from the $\mathrm{C} 2$ spinous process and the $\mathrm{C} 1$ posterior arch. The $\mathrm{C} 1$ and $\mathrm{C} 2$ lateral mass screw and plate fixation was performed on both sides ( $\mathbf{- F i g . ~ 8 C}$ ). Then, the wound was closed without drain.

\section{Postoperative Period}

Postoperatively, the neurological recovery of the patient was rapid. By the end of 2 weeks he could walk without support. 


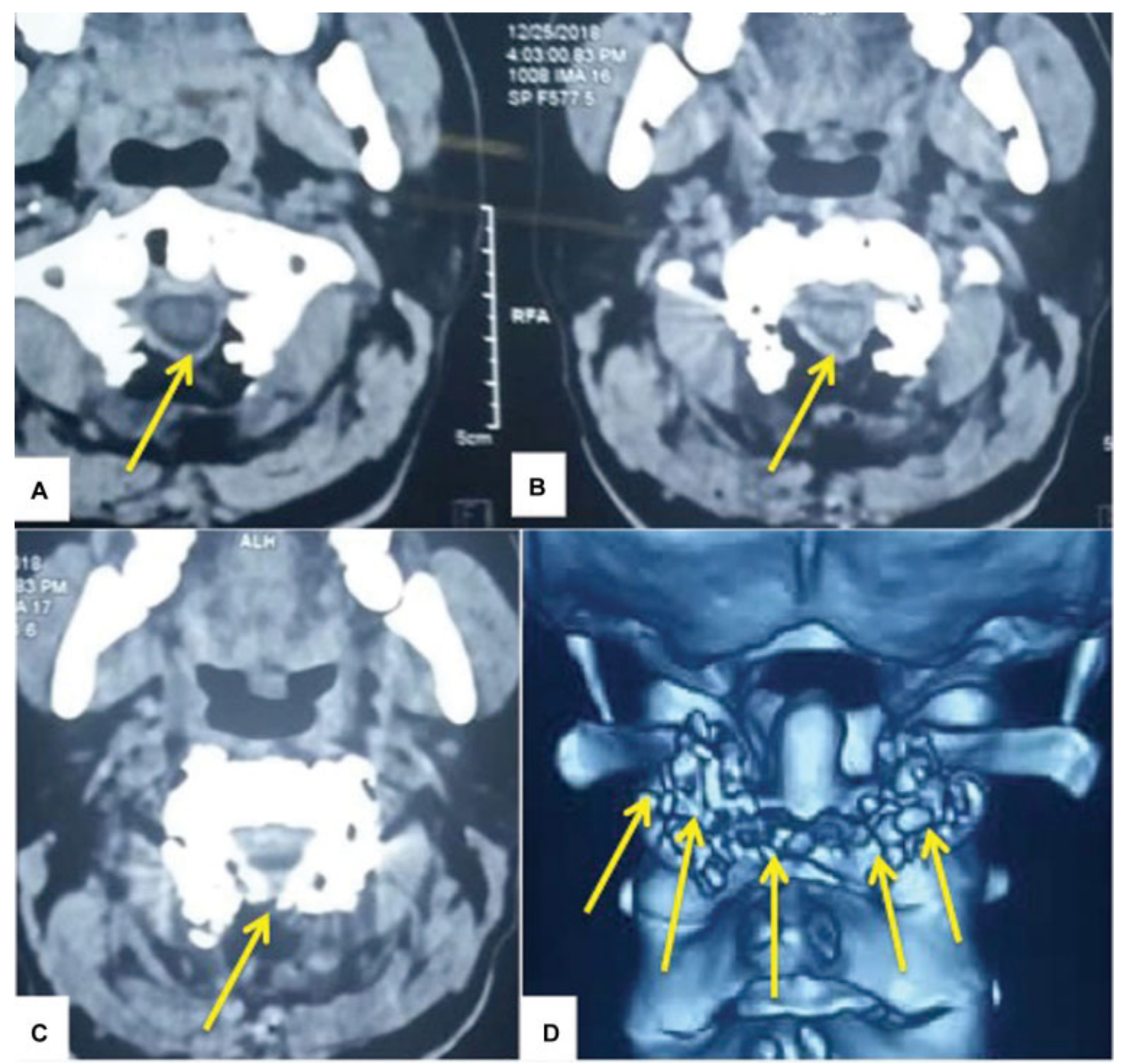

Fig. 7 Postoperative computed tomography scans of the craniovertebral junction, axial views. A, B and C: showing decompression of the spinal cord by removing the $\mathrm{C} 1$ and $\mathrm{C} 2$ accessory facet joints with the $\mathrm{C} 1$ posterior arch (arrow marked); D: 3D computed tomography scans of the craniovertebral junction showing the removal of the $\mathrm{C} 1$ and $\mathrm{C} 2$ accessory facet joints with the $\mathrm{C} 1$ posterior arch, as well as the fixation of the $\mathrm{C} 1$ and $\mathrm{C} 2$ screws and plates and fusion with bone chips (arrow marked).

Six weeks after the operation, he recovered completely. Postoperative CT scans of the CVJ showed C1 and C2 fixation with screws and plates with absence of accessory facets and of the $\mathrm{C} 1$ posterior $\operatorname{arch}(\mathbf{- F i g . ~} 7 \& 8)$.

\section{Discussion}

Unilateral C1 and C2 accessory facet joint was first reported in 2011 by Riesenburger et al. ${ }^{3}$ Bilateral accessory facet joint was first reported by Salunke et al in 2013. ${ }^{4}$ The origin of C1 and $\mathrm{C} 2$ accessory facet is not exactly known. The formation of such a dysmorphic joint suggests an aberration of HOX genes determining articulation. ${ }^{4}$ During the embryological development of the $\mathrm{C} 1$ and $\mathrm{C} 2$, sclerotomes may fuse abnormally posteriorly, followed by the initiation of events at this site that eventually lead to the formation of a morphologically normal synovial joint in an abnormal location. ${ }^{3}$ These are seen posteriorly to the true facets and resemble partially formed joints. The $\mathrm{C} 2$ facet was acutely bent over its isthmus in these patients. ${ }^{5}$ These joints are dysmorphic and partially formed, as evidenced by the absence of the synovial membrane and capsule. However, in our case, peroperatively, the articular cartilage, along with a pannus type of synovial membrane, were seen, although these were not confirmed by the histopathological examination. The function and physiological aspects of these joints are not exactly known. ${ }^{4}$

The first 'unilateral accessory facet' case presented at the age of 35 years old, ${ }^{3}$ and the first 'bilateral accessory facets' case presented at the age of 17 years old. ${ }^{4}$ Their clinical presentation includes neck pain, headaches, and tingling sensation, spasticity and quadriparesis. ${ }^{3-5}$ 


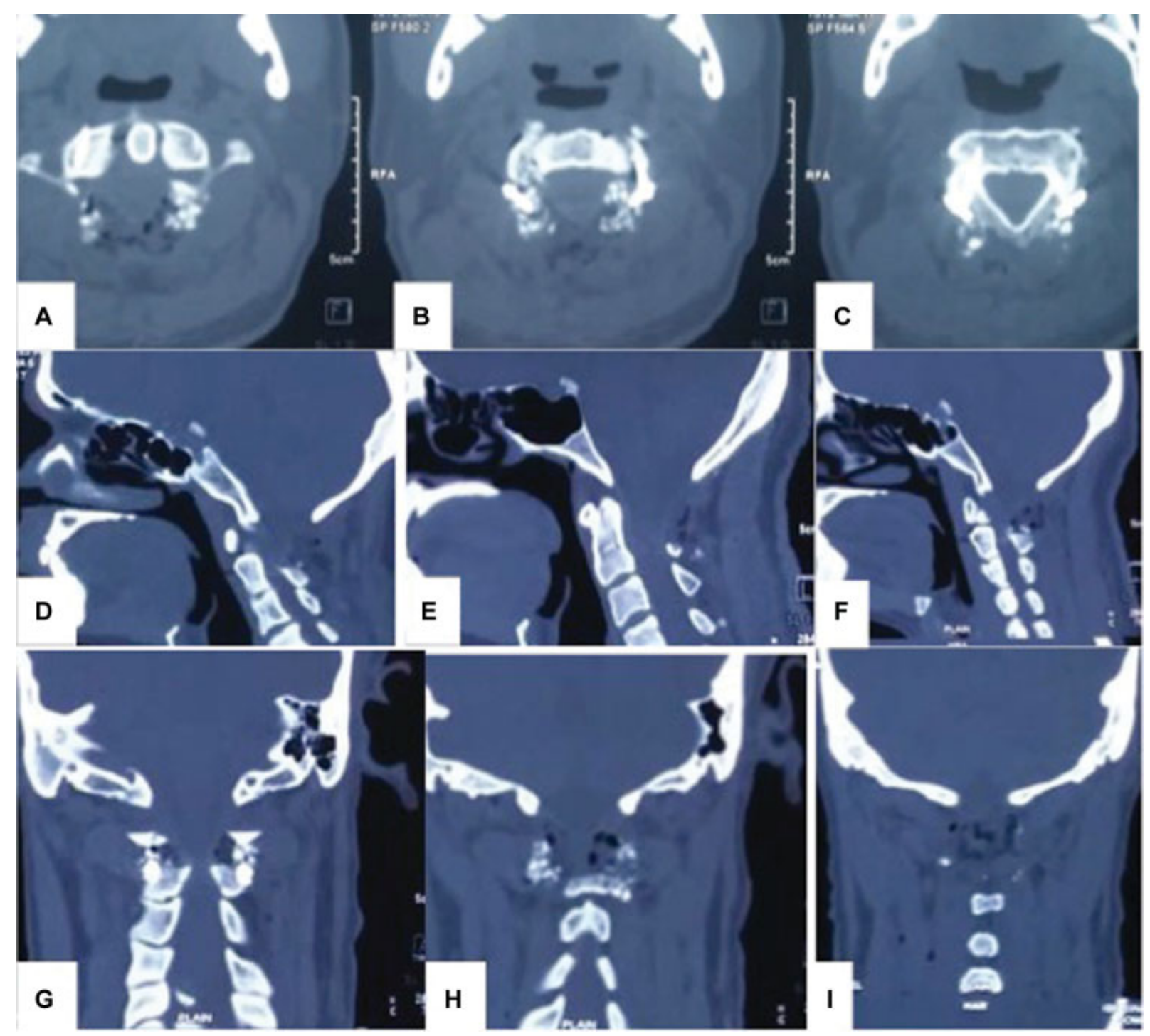

Fig. 8 Computed tomography scans of the craniovertebral junction. A, B and C: axial views; D, E and F: sagittal views; G, H and I: coronal views showing the removal of both accessory $\mathrm{C} 1$ and $\mathrm{C} 2$ facets with the posterior $\mathrm{C} 1$ arch, as well as fixation and fusion.

Plain X-rays may be normal, but sometimes can give very useful information in symptomatic cases like the presented case. Computed tomography scan is used to identify the accessory joint and C1 and C2 instability. Magnetic resonance imaging is used to identify the cord compression. In our case, the accessory facets were also seen in the MRI. In the cases reported in the literature, the accessory facets were associated with $\mathrm{C} 1$ and $\mathrm{C} 2$ congenital instability. ${ }^{5}$ Therefore, atlantoaxial regular facets may be congenitally weak when associated with accessory facet joints, and these facets may provide some stability. The direction of these pseudofacets appeared to counter the abnormal mobility at the $\mathrm{C} 1$ and $\mathrm{C} 2$ true facets. ${ }^{5}$

When symptomatic, the treatment of this condition is the excision of the accessory joint or joints along with fixation and fusion of the $\mathrm{C} 1$ and $\mathrm{C} 2 .^{3,4}$ During the operation, there is a visual hindrance to reach up to the true facets for the placement of spacers and lateral mass screws, requiring extensive drilling. ${ }^{5}$ We think that, peroperatively, the $\mathrm{C} 2$ nerve root and ganglion should be identified by removing the accessory facets completely, and then the surgeon can comfortably and safely manipulate the regular $\mathrm{C} 1$ and $\mathrm{C} 2$ facets for fusion and fixation. More drilling of bone is needed on the $\mathrm{C} 2$ for the proper placement of screws and plates. Area for C2 screw placement is much more than usual. In our case, it seemed that the accessory facets were true synovial joints.

\section{Conflicts of Interests}

The authors have no conflicts of interests to declare.

\section{References}

1 Sahipau RL. Congenital Anomalies of the Craniovertebral Junction.2002. Semin Neurosurg 2002;13(02):111-118 10.1055/s2002-35808

2 Goel A, Sharma P, Dange N, Kulkarni AG. Techniques in the treatment of craniovertebral instability. Neurol India 2005;53 (04):525-533 
3 Riesenburger RI, Klimo P Jr, Yao KC. A fourth atlantoaxial joint: an initial description. Spine J 2011;11(04):e6-e9

4 Salunke P, Futane S, Vaiphei K. Posterior bilateral supernumerary atlanto-axial facets: true or false joint? Spine (Phila Pa 1976) 2013; 38(25):E1633-E1635. doi:10.1097/BRS.0b013e3182a8a603.
5 Salunke P, Futane S, Sharma M, Sahoo S, Kovilapu U, Khandelwal NK. 'Pseudofacets' or 'supernumerary facets' in congenital atlanto-axial dislocation: boon or bane? Eur Spine J 2015;24 (01):80-87 